\title{
Guidelines and pitfalls of refraction microtremor surveys
}

\author{
John N. Louie (iD) A Aasha Pancha • B. Kissane
}

Received: 18 January 2021 / Accepted: 31 May 2021 / Published online: 7 June 2021

(C) The Author(s) 2021, corrected publication 2022

\begin{abstract}
The geotechnical industry has widely adopted the refraction microtremor shear-wave velocity measurement technique, which is accepted by building authorities for evaluation of seismic site class around the world. Clark County and the City of Henderson, Nevada, populated their Earthquake Parcel Map with over 10,000 site measurements for building code enforcement, made over a 3year period. $2 \mathrm{D}$ refraction microtremor analysis now allows engineers to image lateral shear-wave velocity variations and do passive subsurface imaging. Along with experience at a basic level, the ability to identify the "no energy area" and the "minimum-velocity envelope" on the slowness-frequency $(p-f)$ image helps practitioners to assess the quality of their ReMi data and analysis. Guides for
\end{abstract}

\section{Highlights}

- The Refraction Microtremor or ReMi technology provides shear wave velocity profiles useful for earthquake hazard assessment.

- Data collection and interpretation according to listed best

practices provide fast and reliable site characterization.

- Optim Earth and the Univ. of Nevada adapted ReMi to

characterize basins to $>1 \mathrm{~km}$ depth, and for high-density mapping.

J. N. Louie $(\bowtie)$

Nevada Seismological Laboratory, University of Nevada, Reno,

NV, USA

e-mail: louie@seismo.unr.edu

A. Pancha

Aurecon, Wellington, New Zealand

e-mail: Aasha.Pancha@aurecongroup.com

B. Kissane

Optim Earth, Inc.https://www.OptimSoftware.com grading ( $p-f)$ image quality, and for estimating depth sensitivity, velocity-depth tradeoffs, and depth and velocity resolution also assist practitioners in deciding whether their refraction microtremor data will meet their investigation objectives. Commercial refraction microtremor surveys use linear arrays, and a new criterion of $2.2 \%$ minimum microtremor energy in the array direction allows users to assess the likelihood of correct results. Unfortunately, any useful and popular measurement technique can be abused. Practitioners must follow correct data collection, analysis, interpretation, and measurement procedures, or the results cannot be labeled "refraction microtremor" or "ReMi" results. We present some of the common mistakes and provide solutions with the objective of establishing a "best practices" template for getting consistent, reliable models from refraction microtremor measurements.

Keywords COSMOS guidelines · Geotechnical shear velocity $\cdot$ Seismic microzonation $\cdot$ Surface-wave dispersion $\cdot$ Best-practices

\section{Introduction}

The original journal paper on the "refraction microtremor" shear-wave velocity measurement technique emerged in 2001 (Louie 2001). The refraction microtremor method has undergone peer review and has extensively been blind tested against results from borehole measurements, multichannel analysis of sur- 
face waves (MASW), and spectral analysis of surface waves (e.g., Louie 2001; Liu et al. 2005; Stephenson et al. 2005; Thelen et al. 2006). Heath et al. (2006) undertook validation using synthetic data. Since then, building authorities around the world accept refraction microtremor measurements of shear-wave velocity, time-averaged from the surface to $30 \mathrm{~m}$ depth, known as "Vs30", for evaluation of seismic site class (NEHRP 2020) in enforcing building design and performance standards. The method has been widely adopted by the geotechnical industry. Refraction microtremor technology developers continue research on the methodology and have further adapted the method for new applications.

In particular, the refraction microtremor method is capable of efficiently measuring shear-wave velocity at large numbers of sites in heavily urban areas. The University of Nevada has completed transects of closely spaced $(300 \mathrm{~m})$ shear-wave velocity versus depth profiles, to depths exceeding $300 \mathrm{~m}$, across three urban basins. The initial transect across Reno, Nevada, measured 52 velocitydepth profiles along a distance of $15 \mathrm{~km}$ (Scott et al. 2004). A transect in Los Angeles, California, crossed both the San Gabriel and Los Angeles basins with 200 profiles over $60 \mathrm{~km}$ (Fig. 1; Thelen et al. 2006). Transect velocity measurements followed the predictions of Wills et al. (2000) as well as available Rosrine suspensionlogger results from nearby deep boreholes. A transect through Las Vegas, Nevada, measured 47 profiles over a distance of $13 \mathrm{~km}$ (Scott et al. 2006). Examining the large amount of closely spaced shear-velocity data showed they have fractal spatial statistics, similar to downhole measurements (Thelen et al. 2006). Across all three transects, the distributions of previously mapped soil and geologic units do not predict the Vs30 measurements (Scott et al. 2004; Thelen et al. 2006; Scott et al. 2006).

The spatially fractal variance of the closely spaced velocity measurements includes both the epistemic uncertainty of the measurement method and the aleatory uncertainty due to spatial variations of ground conditions. Since these data are characterized as fractal over all spatial frequencies, horizontal as well as vertical, they conform to a self-similar process, meaning variance increases as lag distance increases. These results indicate that the velocity measurements contain aleatory variance at all distances, reflecting the natural heterogeneity of ground velocity properties (Thelen et al. 2006).

Unfortunately, any useful and popular measurement technique can be abused. Practitioners must carefully follow correct data collection, analysis, interpretation, and modeling procedures, or the outcomes cannot be labeled "refraction microtremor" or "ReMi" results. Inexperienced or ill-informed practitioners have at times failed to produce correct shear-wave velocities, due to either improper data acquisition or unsuitable analysis techniques. This paper presents some of the common mistakes, and provides solutions with the objective of establishing a "best practices" template for getting consistent, reliable shear-wave velocity models from refraction microtremor measurements.

The second half of this paper examines recent developments in high-density shear-velocity measurement programs, going far beyond the 300 sites measured in the urban transects to explore spatial variations in velocity; the extension of one-dimensional refraction microtremor profiles into two-dimensional cross-sections; an uncertainty analysis examining the epistemic and aleatory uncertainties of the surface-wave dispersion modeling process; and the extension of refraction microtremor results to depths of $1 \mathrm{~km}$ or more.

\section{Pitfalls and best practices in refraction microtremor}

The past 15 years have seen continuous commercial and academic activity employing refraction microtremor. There are hundreds of users of the refraction microtremor technique around the world. Users range from close research and development colleagues; through academic and commercial license holders of the SeisOpt ${ }^{\mathrm{TM}}$ ReMi technology and their students and employees; to academics and practitioners who are not license holders but are endeavoring to perform refraction microtremor analyses independently, or with other seismic software packages. This section is addressed especially to those users who have not been able to obtain all the experience and training from which our fellow researchers and long-term license holders have benefitted. Here we address pitfalls within four phases of ReMi analysis: data collection; processing; dispersion picking; and modeling. 


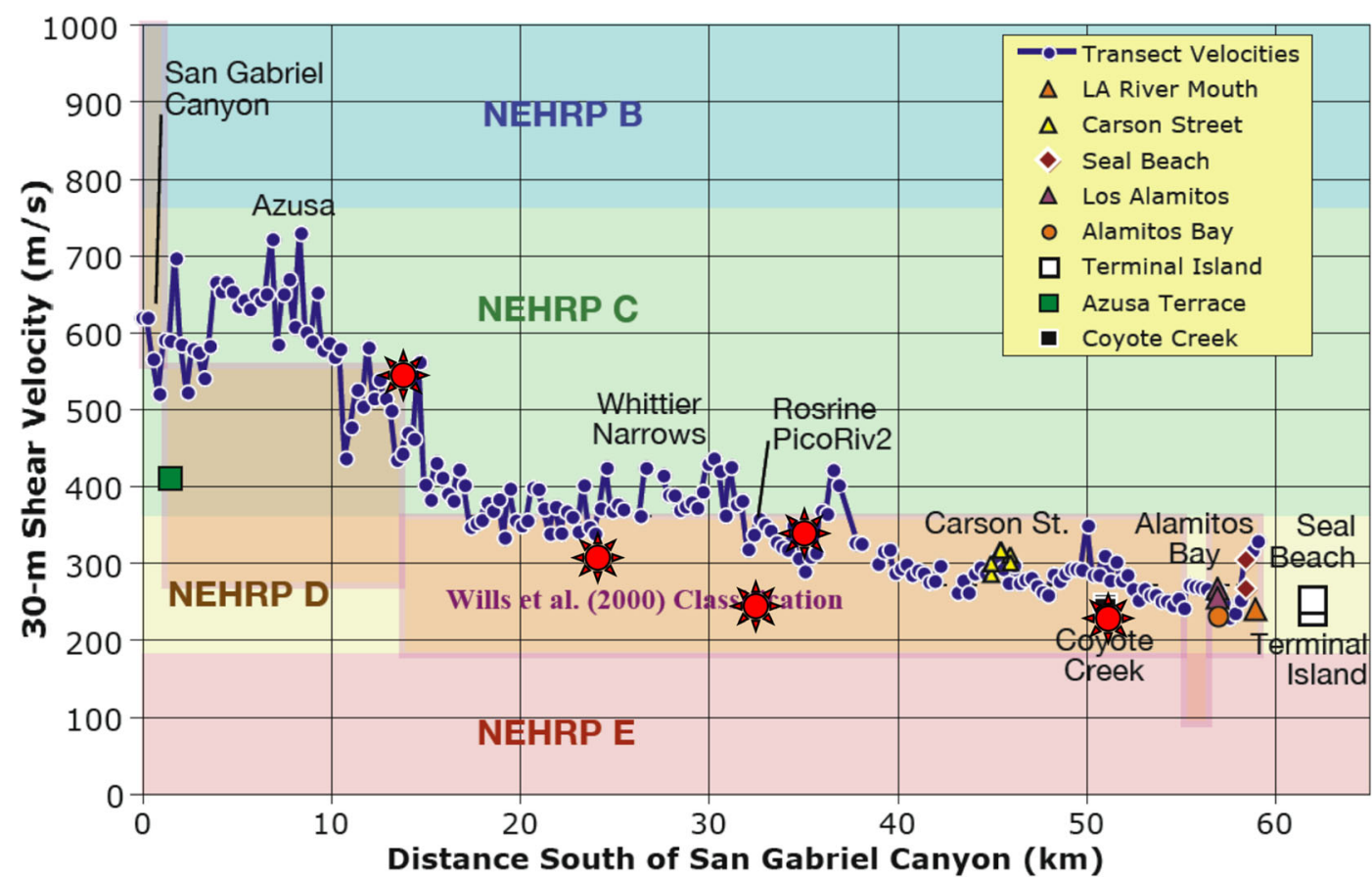

Fig. 1 Time-averaged shear-wave seismic velocity to $30 \mathrm{~m}$ depth (Vs30) values measured by the San Gabriel River ReMi transect across the Los Angeles Basin (Thelen et al. 2006). Purple dots represent the Vs30 values for 200 transect array placements on the

\subsection{Recommendations for instrumentation, and pitfalls} of ReMi array data collection

Recommendations for instrumentation Standard commercial ReMi surveys for earthquake-hazard and building-code compliance purposes employ standard multichannel seismic-refraction recording arrays that include:

- At least 12 channels of geophones; 24 is better.

- A total array length of $88 \mathrm{~m}$ or more (geophone spacing of at least $8 \mathrm{~m}$, with 12 channels). Deploy geophones beyond the site boundaries if necessary, to make the array length at least twice the target depth.

- Vertical-component ground-velocity geophones or accelerometers with significant sensitivity and fidelity at frequencies between $5 \mathrm{~Hz}$ and $50 \mathrm{~Hz}$. All channels should have the same model and frequency of geophone, but geophone response does not need calibration. Appropriate geophones are termed "low-frequency" and must be carefully leveled when planted for each array. river levee at $300 \mathrm{~m}$ intervals. Other locations are away from the active river channel. Bright red stars show nearby Rosrine suspension-logger results from deep boreholes

- Geophone locations evenly spaced in a straight line and along a constant grade, to a tolerance of $5 \%$ of the array length. For an $88 \mathrm{~m}$ array, any geophones more than $4 \mathrm{~m}$ off the average spacing, the average line, or average grade must be located relative to the other geophones to a precision of $30 \mathrm{~cm}$. Absolute location of the array center is needed to a tolerance of $5 \mathrm{~m}$, and the array azimuth needs to be determined to $5^{\circ}$ tolerance.

- Multichannel records at least $30 \mathrm{~s}$ long, with a timesample interval between 0.5 and $4 \mathrm{~ms}$. Relative timing accuracy between channels needs to be at least as precise as the time-sample interval, but the absolute time of each record only needs to be known to the nearest $5 \mathrm{~min}$.

- At least 21-bit digital precision for the amplitude of each recorded time sample, integer or float.

- Recording at least ten records of at least 30 contiguous seconds each.

- Adding untimed sledgehammer blows to a strike plate, $10-20 \mathrm{~m}$ off each end of the array, during the recording of a majority of the records.

- At sites with a shallow water table and very soft surficial sediments, also collect $\mathrm{P}$-wave seismic 
refraction data to establish the depth of water table (i.e., depth where $\mathrm{Vp}>1500 \mathrm{~m} / \mathrm{s}$ ) to be used as a constraint during modeling of dispersion data.

Pitfalls: Lines too short Practitioners sometimes use a linear refraction microtremor array that is too short, given their target depth. Total array length should generally be greater than twice the maximum target depth. Rayleigh waves are most sensitive to velocities and structures that are within a half-wavelength of the surface. To properly time the velocity of such a wave, the sensor array needs to be at least as long as the wavelength.

Geophone spacing not appropriate Practitioners sometimes use geophone spacings that are not suitable to image the targeted subsurface features. For example, to image $2 \mathrm{~m}$ thick material layers in the upper 5 to $10 \mathrm{~m}$ of the surface, geophone spacing should be a maximum of $2 \mathrm{~m}$. Use of greater spacings, of $3 \mathrm{~m}$ for example, will not capture the short wavelengths required to image and constrain small scale features.

Recording time too short Practitioners who have experience with active-source Multichannel Analysis of Surface Waves (MASW) surveys sometimes assume that the 4- or 5-s-long hammer-source records recorded for that technique can also be used for ReMi analysis. This may be true only if the maximum target depth is less than $30 \mathrm{~m}$. Standard practice for commercial ReMi, reliably getting the time-averaged shear-wave velocity property to a depth of $30 \mathrm{~m}$ or $100 \mathrm{ft}$, is to record ten records at least $30 \mathrm{~s}$ long each. Longer records improve the frequency resolution of the $p-f$ image and thus of the dispersion curve. For structure at $500 \mathrm{~m}$ or greater depth, 60 to $120 \mathrm{~s}$ records are desirable.

Site too quiet Urban areas are where the ReMi technology works most easily. Naphan et al. (2019) found that urban areas reliably provide the minimum $2.25 \%$ of energy propagating in the direction along the linear array. On the other hand, remote, quiet locations can be tricky to survey. Such sites can yield good ReMi analyses if the survey party adds waves by hammering off the end of the array, or by driving their largest truck along the array. Sledgehammer blows mostly help define the dispersion curve above $10 \mathrm{~Hz}$, while driving a heavy truck can yield broad-band microtremor down to
$2 \mathrm{~Hz}$. Jogging up and down the array has also been found to be effective. During analysis, take note of which 30-s records have added sources. It might be necessary to process and pick those records differently.

Bad geophone sensors Seismic quality control is critical to a successful ReMi survey. Test your array after installation with some hammer blows to check for bad or unconnected geophone sensors. Any geophone with a natural frequency of less than $8 \mathrm{~Hz}$ needs careful leveling. While it is often easy to achieve a good geophone plant for ReMi with a 4-in spike into turf, with no need to remove the turf; brushy or sandy sites may require shovel work to properly bury each leveled geophone. Rocky or cobbled sites require particular care to get good geophone connection with the ground and keep them from rocking on their spikes. ReMi surveys across pavements are easy, with tripod geophone bases.

No $Q C$ Accessing a field site is often the most expensive part of ReMi surveying. Do not leave the site until you are assured that your data are adequate for your objectives. Take the extra $15 \mathrm{~min}$ and try test processing before pulling the array. Examine the $p-f$ images of at least a few records. If you cannot recognize the minimum-velocity envelope, across the range of frequencies you need, consider adjusting your array parameters, and additional recording.

\subsection{Pitfalls of transformation to ReMi $p-f$ images}

The objective of deriving the $p-f$ image is to recognize the minimum-velocity envelope. The minimum-velocity envelope is not subjective and can always be identified on the ReMi $p$ - $f$ image, so long as two conditions are met: 1 ) the microtremor energy is not entirely unidirectional, with at least a few percent of the wave energy traveling in the direction of the linear array (Naphan et al. 2019); and 2) at low apparent velocities across a range of frequencies, a region of near-zero energy appears on the $p$ - $f$ image, often with a purple color as in the examples of Figs. 2 and 3. Since the apparent velocity of the Rayleigh wave on the microtremor array records can be higher than, but can never be lower than the Rayleigh phase velocity at a given frequency, the low-energy and low-spectral-ratio area must be bounded at the top by the minimum-velocity envelope. The upper bound of the dark-blue and purple, low-energy area of a $p-f$ image usually yields dispersion picks with the smallest uncertainty. 
High Vmin The blue or purple low-spectral-ratio region may not appear on the ReMi $p$-f image if the minimum velocity of the analysis is set too high. Start with a low value for Vmin such as $100 \mathrm{~m} / \mathrm{s}$ to check, then repeat and refine. The most interpretable $p$-f image will show a clear low-spectral-ratio region, but occupying no more than a third of the $p$-f image. Be careful to check whether the observed dispersion curve imaged is not a higher mode by using a lower Vmin. Often where there is a prominent velocity contrast (e.g., very low velocities above competent bedrock), a clear series of higher modes are generated.

Low fmax Start high to check, perhaps at 50 or $100 \mathrm{~Hz}$. Though most projects will not be interested in dispersion measurements above $30 \mathrm{~Hz}$, you may find a clear minimum-velocity envelope at higher frequencies. That can guide your interpretation of the dispersion at your frequencies of interest.

Summing in bad records When summing the individual $p-f$ images together for final picking of the dispersion curve, some records may not produce $p-f$ images with clear low-spectral-ratio regions. You should try summing with and without these records, to see which strategy yields the clearest minimum-velocity envelope.

No tests Try forward-only direction of analysis, reverseonly, and both on all records. See which strategy yields the broadest-band low-spectral-ratio region, and thus the clearest minimum-velocity envelope. You can pick dispersion just on the records where the envelope is clear, and only at the clear frequencies on each $p-f$ image, combining the picks later for modeling. This ensures correct capture of the minimum-velocity envelope.

Linear velocity transformations Practitioners sometimes attempt to make ReMi analyses with MASW software, which plots the wavefield transformation on a linear scale of velocity, rather than the linear slowness scale that ReMi $p$ - $f$ images use. The linear velocity scale is appropriate for MASW surveys, with their active sources in-line with the recording array. In a microtremor survey, most of the Rayleigh wave energy is not traveling in the direction of the linear array. ReMi $p-f$ images use a linear slowness scale to identify the energy arriving broadside to the array, with zero slowness and infinite apparent velocity, such as within the red oval on Fig. 2. A plot with a linear velocity scale cannot show the energy at infinite apparent velocity, while a ReMi $p$ - $f$ image will show it clearly. Although you will not be making any dispersion picks along such broadside energy, it is helpful to identify the frequency range of such effects, as they can add uncertainty to the minimum-velocity envelope.

\subsection{Pitfalls of interpreting ReMi $p$-f images for dispersion}

Picking along spectral maxima Always make dispersion picks along the minimum-velocity envelope. In Fig. 3 , the red, high-spectral-ratio features, or their lower bounds, do not help identify the minimum-velocity envelope. Once the interpreter has identified that low-ratio region, and picked dispersion across the top of it, they are often able to extend dispersion picks into lower and higher-frequency areas of the $p-f$ image, that do not show near-zero ratio below. The interpreter's experience with modeling dispersion picks, and identifying the slowness at which the steepest gradient of ratio appears at each frequency (as suggested by Pancha et al. 2008), can aid this process. Only pick at ratio maxima where you know you have a record and a frequency range dominated by an inline source. Even so, you will notice that the picked dispersion velocity at the peaks is only $3-5 \%$ higher than on the minimum-velocity envelope; that observation will assist you with describing dispersion uncertainties.

Detailed analyses by Pancha et al. (2008) demonstrated that dispersion picks at a given frequency (along a vertical line in Figs. 2 or 3) should generally be made where the gradient of the power-slowness profile is steepest. In the presence of energy arriving equally from all directions along the liner array, the shape of the power-slowness profiles would be that of a half cosine curve, with an abrupt vertical cut-off occurring at the true slowness at a ratio maximum, with the remaining energy dispersed over smaller slownesses above this. This idealized profile would be obtained if ambient noise records over long time periods were summed to ensure that energy from all azimuths were obtained, with a sharper cut-off for longer recording intervals. According to Heisenberg's uncertainty principle, frequency is only infinitely precise for recordings of infinite duration (Claerbout 1992).

Power-slowness curves from real-world examples do not exhibit this form, but instead have a tail occurring at slownesses less than those of the steep gradients of the minimum-velocity envelope-above the envelope in 


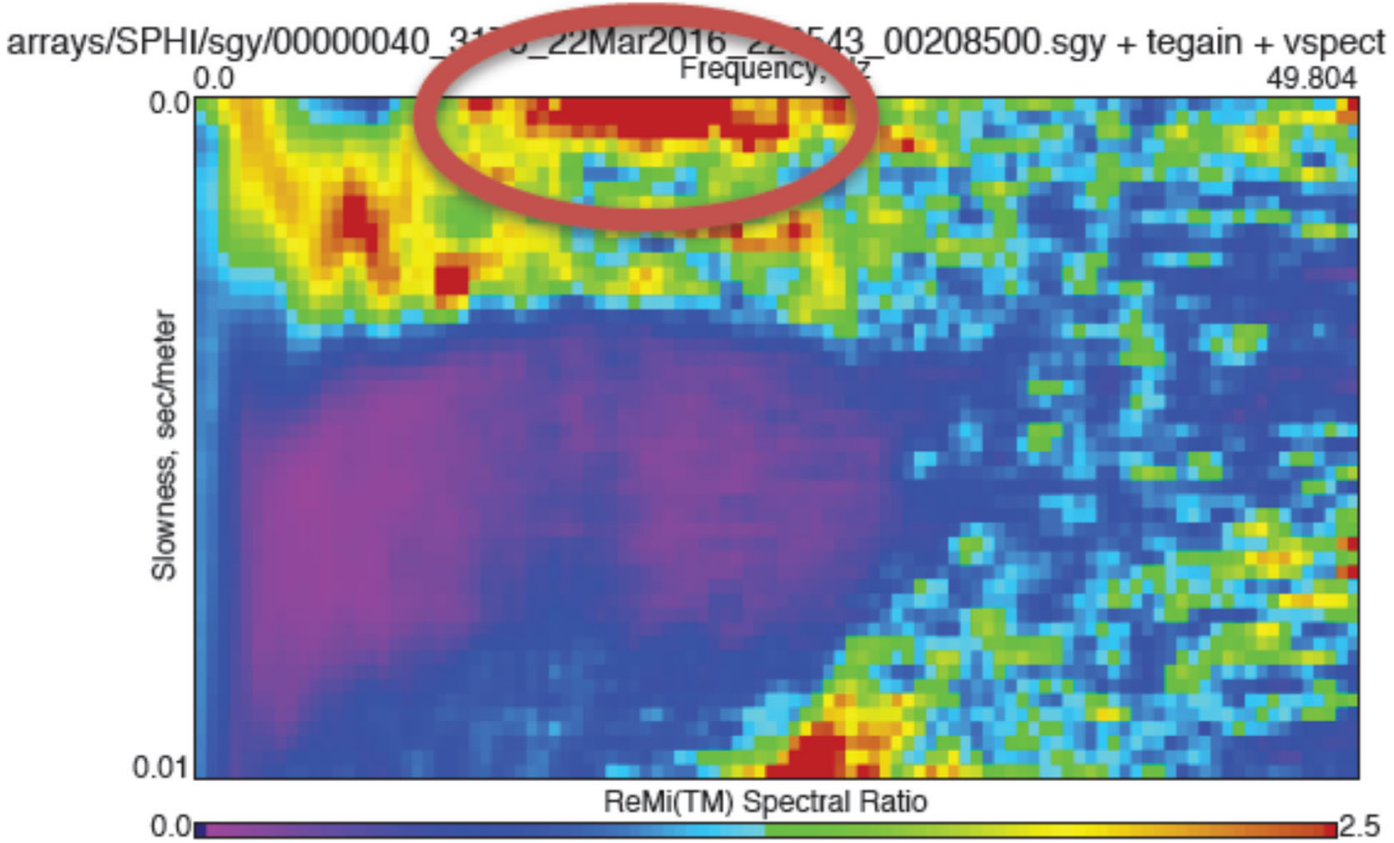

Fig. 2 Example of a ReMi $p$ - $f$ slowness-frequency image derived from wavefield transformation of a microtremor record. Frequency increases to the right, from 0.0 to $50 \mathrm{~Hz}$; slowness increases linearly down, from $0.0 \mathrm{~s} / \mathrm{m}$ at the top to $0.01 \mathrm{~s} / \mathrm{m}$ at the bottom. Cool colors indicate a low ratio of energy at a combination of slowness and frequency, compared to the total energy across all slownesses at that frequency. Purple is near-zero spectral ratio; warm colors mark high spectral ratios and the predominant energy

Figs. 2 and 3. This is due to four factors. The first, which is discussed by Louie (2001), is due to dominance of energy arriving obliquely to the array. This causes the peak power ratio along the dispersion curve to occur at in the record. Since the slowness is the inverse of the apparent wave velocity along the array, velocity increases non-linearly upwards, from $100 \mathrm{~m} / \mathrm{s}$ at the bottom to infinity at the top. An infinite apparent velocity simply means a wave front is hitting the array broadside, arriving simultaneously at all sensors. The red oval marks a strong such simultaneous wave, here between 15 and $30 \mathrm{~Hz}$. The minimum-velocity envelope is still clear there, between the green and purple colors

higher apparent velocity, with energy arriving more parallel to the array contributing to the commonly observed tail. The second is due to discretization of slowness (Louie 2001). The third factor contributing to this



Fig. 3 (left) Close-up of a ReMi $p$ - $f$ slowness-frequency image illustrating good and bad fundamental-mode Rayleigh-wave dispersion picks. The good picks are made by hand, by an experienced interpreter along the minimum-velocity envelope; the bad picks could be made automatically, at spectral-ratio peaks that

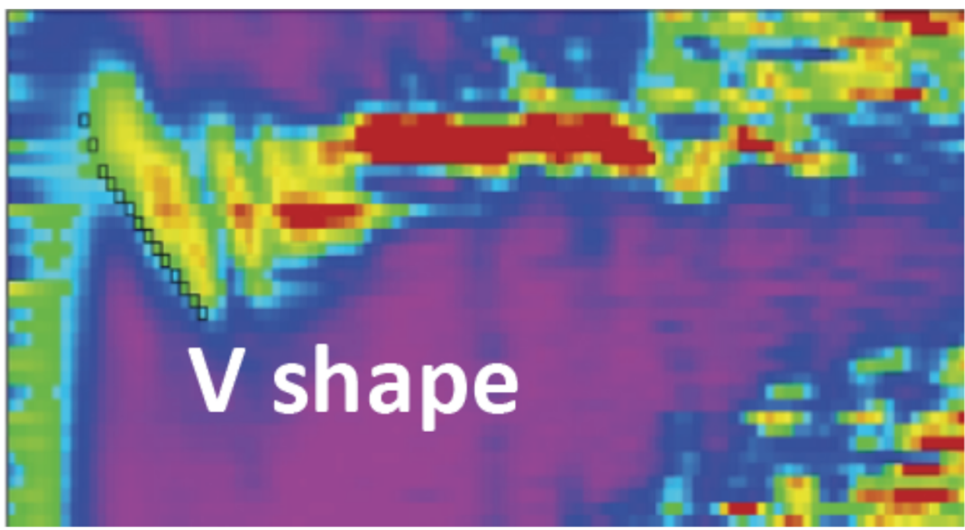

likely are following higher modes. (right) Close-up of another $p-f$ image illustrating the "V" shape that often clearly demonstrates an inversion in shear-wave velocity with depth. Further examples are shown in Fig. 6 below 
low-velocity tail is the presence of lateral threedimensional shear-wave velocity heterogeneity along the array. The sharp idealized lower boundary of the dispersion curve could only occur if we were dealing with a one-dimensional case with infinite frequency bandwidth, and thus infinite recorded time.

The fourth and perhaps the most pronounced factor contributing to the absence of the sharp defining boundary is the finite bandwidth of the measurable frequencies. The resolution of the Fresnel zone is frequencydependent and therefore limited due to Heisenberg's uncertainty principle (Claerbout 1992), resulting in the smoothing of the minimum boundary of the powerslowness curve. Absence of a sharp cut off in the power-slowness curve, as observed in the red-topurple color gradations of Fig. 2, is also observed in the ReMi analysis of synthetically generated ground motions (Heath et al. 2006; Naphan et al. 2019). Due to the combined effects of these four factors on smoothing the theoretically sharp minimum bound of the dispersion curve, the suggestion by Louie (2001) that the ideal pick is that located where the spectral ratio is high and the gradient is steepest, seems plausible.

Picking into gaps Skip over frequency bands with too little energy along the minimum-velocity envelope, as the white line in Fig. 3 illustrates. Picking up into the "scallops" above the envelope and above the lowspectral-ratio area will produce a dispersion curve that no model will fit. Dispersion curves are smooth.

Picking few records Make sure you are picking at the minimum-velocity envelope across all records and tests. Different records have different microtremor conditions; each one that shows a clear blue or purple low-spectralratio region will have an interpretable minimumvelocity envelope, and thus will contain some information on the dispersion curve. You can make dispersion picks wherever the envelope is clear, and later combine the picks for modeling.

Auto-picking in MASW software Automatic picking of dispersion curves is appropriate for MASW surveys, having strong active sources located in-line with the arrays. Such sources produce strong energy peaks along the dispersion curve. No reliable automatic picking method has yet been developed for the minimumvelocity envelopes in refraction microtremor $p$ - $f$ images. Compare the white minimum-velocity envelope with the dashed red line along the peaks, on the left side of Fig. 3. Using MASW software to make automatic dispersion picks at peaks in the ReMi $p$-f image is unlikely to produce valid dispersion data, especially at the lower frequencies. Picking the dispersion phase velocity by hand allows the best interpretation of the curve.

Picking a higher mode Higher-mode surface waves will appear above the minimum-velocity envelope, though they may intersect it as in Fig. 3. Check using lower values of Vmin to make sure the $p$ - $f$ plot has identified the fundamental mode. Then pick the minimumvelocity envelope, for the fundamental Rayleigh mode.

Ignoring directional effects on ReMi analysis An obstacle shared by all passive surface wave analysis methods is the unknown source-receiver geometry, and possible adverse effects on apparent velocities. Particularly in the case of linear array geometry, the risk is that velocities will be overestimated if the direction of energy propagation is not approximately parallel to the array. Refraction microtremor is a passive method that utilizes a linear array geometry. Naphan et al. (2019) took an experimental approach to directional analysis that makes use of a 2-D array configuration consisting of two linear arrays, arranged orthogonally in an "L" configuration. Their 3-D synthetic wave modeling using this configuration explored a variety of source-receiver orientations for directional effects. The analysis demonstrated the most extreme cases of directional preference and the way they present during processing, as well as the ideal case where the wavefield is omni-directional. Based on the addition of omni-directional source energy to the worst-case synthetic scenario, the synthetic modeling made a determination of the minimum proportion of energy necessary to have propagated in-line with the array to achieve an accurate result.

This approach indicates the appropriate proportion to be $15 \%$ of total rms amplitude, or $2.3 \%$ of total wave energy (Naphan et al. 2019). In the case of several different experimental surveys collected in the RenoSparks, Nevada area using this "L" array configuration, directional effects similar to those exhibited in synthetic models do not appear. A statistical evaluation from over 10,700 ReMi surveys, collected by Optim for the Clark County Parcel Map by Pancha et al. (2017a, b) demonstrate similar statistical distributions between geotechnical estimates of Vs30, regardless of predominant array orientation. These and other empirical results suggest 
that in and near urban sites rich in microtremor noise, the proposed $15 \%$ of required omni-directional energy is likely present, and ReMi will accurately estimate Vs profiles given the proper collection and processing techniques described here.

Thus, the noise field need not be directionally uniform or omnidirectional. Successful ReMi results can still be obtained at locations where there is a dominant source towards an unknown single azimuth. All that is required is that some of the recorded noise - a minimum of $2.3 \%$ of the energy - be propagating along the linear array, which will be recovered by the analysis. This long-array energy will be evident in the $p$ - $f$ spectral plots along minimum-velocity envelope and defines the true fundamental-mode phase velocity.

\subsection{Pitfalls of modeling dispersion for velocity profiles}

Recent results from the InterPACIFIC project suggest that surface-wave surveying methods, whether they use an active source or a microtremor source, can often obtain very similar dispersion data over a wide band of frequencies (Garofalo et al. 2016). It is in modeling the shear-wave-velocity versus depth "Vs(z)" profile from the dispersion curve that it is difficult to get different methods to agree, even when the modeling is done by very experienced practitioners. Refraction microtremor shares these characteristics of stable dispersion results and less certain $\mathrm{Vs}(\mathrm{z})$ profiles. ReMi practitioners should expect to obtain stable, reliably accurate dispersion data without extreme levels of effort (e.g., stochastic development of thousands of alternative $\mathrm{Vs}(\mathrm{z})$ profiles), following the best practices outlined above. Observing the quality and the uncertainties in the dispersion data at different frequencies is a fairly cut-and-dried procedure. It is the modeling of ReMi dispersion data for $\mathrm{Vs}(\mathrm{z})$ profiles that requires extensive experience, training, and professional judgement.

Modeling velocity profiles from dispersion data can be fraught with uncertainty. Experienced ReMi modelers, just as with the InterPACIFIC project (Garofalo et al. 2016), can and do produce different profiles from identical dispersion data. It can be very difficult to determine what features of the modeled profiles are most reliable. Additional prior constraints on the geology and bedrock velocities, or interface depths or thicknesses of prominent layers from borehole data, assist in defining the most plausible range of possible models for a site.
For very soft sites where the water table is shallow but not evident at the surface, it is helpful to constrain the depth of the water table (where $\mathrm{Vp}>1500 \mathrm{~m} / \mathrm{s}$ ) with a P-wave seismic refraction survey. Such a survey can often be made with minimal additional effort during the ReMi array deployment. Water table depth will add knowledge of large changes in $\mathrm{Vp} / \mathrm{Vs}$ ratios that often occur at the water table, allowing more precise modeling.

Experience suggests several guidelines for interpreting the methodologic, epistemic uncertainties of $\mathrm{Vs}(\mathrm{z})$ profiles modeled from ReMi dispersion data. For a well-fit $\mathrm{Vs}(\mathrm{z})$ model with just a few velocities, and having velocities that only increase with depth, interface depths and layer velocity values are reliable to $\pm 10 \%$. The presence of many interfaces, or the presence of velocity inversions with depth, substantially decreases confidence in any individual depth or velocity value. Velocity inversions demonstrate an "equivalence" problem, where lowering the velocity or thickening the lowvelocity layer can produce the same increase in verticalwave travel time, allowing an infinity of possible models to fit the dispersion data equally well. Such cases need corroborating data to increase confidence in velocity or depth values.

On the other hand, practitioners report great stability with summary velocity values derived from ReMi dispersion data. The most common summary velocity value is the Vs30 depth-averaged velocity used in the NEHRP (2020) provisions of the Building Code. Figure 4 shows an example of Vs30 measurements made and interpreted by an alternative crew at the same place and time as 93 out of 10,722 sites measured for the Clark County Parcel Map (Pancha et al. 2017a), without knowledge of the results of the map production crew. For 87 of the 93 Vs 30 measurements, the independent results agreed within $\pm 10 \%$. The corroborating sites exhibit a huge range of Vs30 values, over a factor of 5. As well, the 93 sites included sites with velocity inversions, common in Las Vegas.

The fact that ReMi Vs30 measurements are more stable and reliable than individual depths or velocities in a $\operatorname{Vs}(\mathrm{z})$ profile suggests two more guidelines: 1) an isolated ReMi measurement of Vs30 at a site unfamiliar to the practitioner can be trusted to $\pm 10 \%$ so long as the practitioner is experienced enough to recognize reliable ReMi data and analysis results. 2) Isolated ReMi measurements of interface depth or layer velocity may not be reliable and need checking against corroborating 
Fig. 4 Results of 93 blind tests conducted during the 2007-2010 Earthquake Parcel Mapping of Clark County (Pancha et al. 2017a), demonstrating some of the epistemic uncertainty of ReMi analysis for depth-averaged velocities such as Vs30. A "Blind" second crew ran each test at the same time and place as a production "Map" measurement; with equipment, data collection, processing, interpretation, and dispersion modeling personnel and analyses entirely separate from the "Map" crew. The Vs30 (Vs100ft) results have 6 of 93 blind Vs30 values $>10 \%$ off the Map Vs30 values, with a $13.55 \%$ maximum difference. The RMS difference is $4.92 \%$, with a $0.26 \%$ bias of average. The light blue envelopes mark $\pm 10 \%$ difference

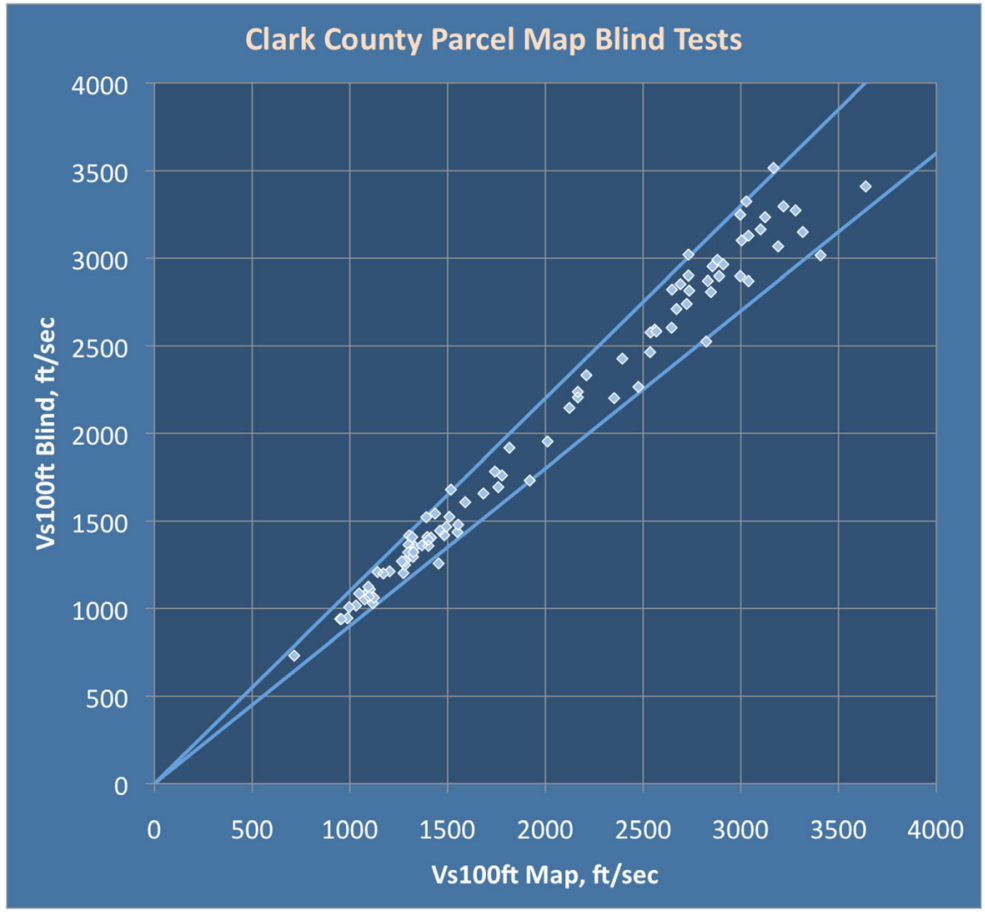

data. The best practice in an unfamiliar area is to make a ReMi measurement coincident with a boring or penetrometer test, and then make additional ReMi measurements, closely spaced, that can carry the corroboration away from the co-located tests.

Ignoring corroborating data Leave blind tests to the researchers; proper engineering practice and due diligence require practitioners to always make use of all the information on a site that they have. Interactive ReMi forward-modeling tools and procedures are built to easily accommodate corroborating and constraining data. These may be interface depths from borehole data or road cuts, or knowledge of the average velocity for bedrock of specific areas. If ReMi is the first geotechnical measurement made at a site, as soon as additional investigations have returned results, the practitioner should re-model the ReMi dispersion data considering the corroborating data.

Overfitting Do not fit all the dispersion picks exactly; they all have a finite uncertainty. Occam's Razor applies, so create the simplest velocity profile that fits each dispersion pick in accord with its uncertainty. Overfitting is often a weakness of the use of automated inversion packages, which may ignore the finite uncertainty of the dispersion data, and do not allow manual testing of the data sensitivity to velocity-depth trade-offs, or the incorporation of prior data such as bedrock velocities or approximate interface depths and thicknesses. If automatic inversions are obtained, use forward modeling packages to check the validity of very thin layers, noting that the minimum resolvable layer thickness increases with depth.

Spurious inversions Learn to recognize the V shape in the $p-f$ slowness-frequency image that demands a velocity inversion with depth, as shown on the right side of Fig. 3. Without that direct evidence in the $p$-fimage, you may be able to include a velocity inversion in your profile, but the ReMi dispersion curve does not verify the inversion. In the absence of the $\mathrm{V}$ shape in the $p-f$ image, only include a velocity inversion if corroborating data demand it.

\section{Recent developments in refraction microtremor}

\subsection{The Clark County Earthquake Parcel Map}

The building departments of Clark County and the City of Henderson, Nevada, contracted in 2007 with the 
Nevada System of Higher Education and Optim to make standardized Vs30 measurements using the ReMi method across $1500 \mathrm{~km}^{2}$ of the Las Vegas urban area within 3 years, at over 10,000 sites (Fig. 5). With a spacing between measurement sites of $300 \mathrm{~m}$ or less, the Parcel Map classifies every parcel on the NEHRP scale (Louie et al. 2011). While Vs30 average values are unable to capture all the aleatory variability in the shallow surface that affect site conditions, the parcel mapping exposed details of localized harder and softer locations (Louie et al. 2011, 2012). Identification of such anomalies is only possible through densely spaced direct measurements of shallow shear-wave velocities at the parcel scale. The detailed Vs30 mapping also delineated the location and boundaries of a previously unknown buried alluvial fan surface (Pancha et al. 2017a, b), which may be associated with the Blue Diamond landslide (Page et al. 1998). The detailed Parcel Map shows that current parametric approaches applied to create site-condition maps cannot account for distinctions between closely related units, and fail where relationships between the parameters and velocity vary spatially (Thelen et al. 2006; Louie et al. 2012; Pancha et al. 2017a, b). The development of an efficient (\$20 per Clark County household) production-scale shear-wave-velocity measurement method allowed comprehensive and consistent enforcement of the NEHRP provisions of the building code across the entire community. The Parcel Map enabled small building projects the same access to Vs30 information as large projects (Pancha et al. 2017a).

The Clark County Parcel Map achieved a nearly complete geotechnical-velocity characterization of the majority of Las Vegas Valley (Fig. 5; Louie et al. 2011, 2012). Such detailed 3D characterization is unprecedented. Together with earlier results on the thickness of Quaternary and Tertiary basin sediments underlying Las Vegas (Langenheim et al. 1998, 2001), the city may well be the best-characterized in the world for $3 \mathrm{D}$

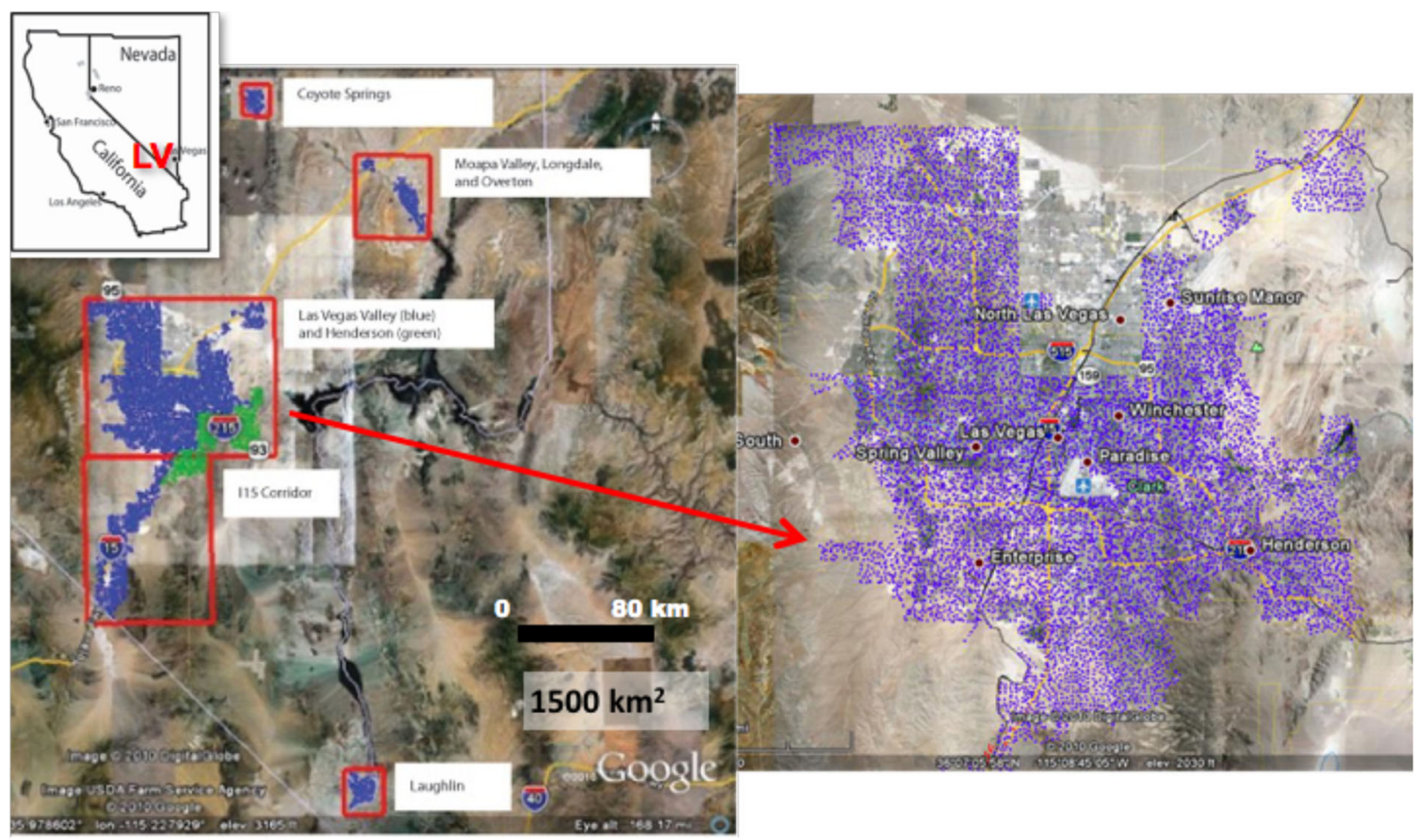

Fig. 5 (left) Map showing the locations of $>10,700$ ReMi array deployments measuring shallow shear-wave velocities for the Earthquake Parcel Mapping projects undertaken by Clark County (blue dots) and the City of Henderson (green dots), in southern Nevada (LV in index map). The projects assessed a total of 1500 $\mathrm{km}^{2}$ of currently urbanized areas of Las Vegas Valley and central Laughlin, as well as exurban areas of future development such as outer Laughlin, the Interstate-15 highway corridor, Moapa Valley, and Coyote Springs. (right) Larger-scale map showing the locations of about 9,000 Parcel Mapping ReMi arrays in Las Vegas Valley. No arrays could be placed on the active runways or ramps of the LAS McCarran International Airport; and funding was not available to cover the City of North Las Vegas. Within the 1500 $\mathrm{km}^{2}$ area covered, the maximum distance between arrays was 300 $\mathrm{m}$. The Parcel Map is freely available from the OpenWeb GIS interface at http://www.clarkcountynv.gov 
physics-based prediction of earthquake shaking. Incorporation of the full Parcel Map was required to effectively simulate the $1992 \mathrm{M}_{\mathrm{L}}$ 5.6-5.8 Little Skull Mountain earthquake $120 \mathrm{~km}$ northwest of Las Vegas and the ground shaking it caused within the city (Flinchum et al. 2014). Peak ground velocities predicted by the 3D model matched what was recorded, to closer than a factor of two. Replacing default geotechnical velocities with the Parcel Map velocities in a sensitivity test produced PGV amplifications of $5 \%$ to $11 \%$ in places, even at low frequencies of $0.1 \mathrm{~Hz}$. In local-scenario sensitivity tests at $0.5 \mathrm{~Hz}$, the aleatory variations measured by the Clark County Parcel Map produced PGV amplifications and de-amplifications of factors of two (Louie 2015).

\subsection{Two-dimensional refraction microtremor sections}

A new 2D refraction microtremor analysis now allows engineers to image lateral shear-wave velocity variations and preform passive subsurface imaging.
Recording refraction microtremor records on an array of 24 or more sensors allows an experienced analyst to carry out effective ReMi analyses on overlapping subarrays (Fig. 6). Starting with a dispersion curve and modeled velocity profile determined from the entire array, the $p-f$ images from the sub-arrays can yield variations in the phase velocity of the dispersion curve, along the array. The interpretation and modeling of the fundamental-mode Rayleigh dispersion still uses the 1D theory originally set out for refraction microtremor (Louie 2001). Because the sub-arrays are shorter than the entire array, $p-f$ images derived from them are often more difficult to interpret. However, the differential analysis can reveal surprisingly sharp lateral contrasts in velocity, showing in some cases factor-of-two lateral changes over distances as small as $10 \%$ of the array length. Since the survey is still entirely passive, the additional information does not come at the expense of additional field effort, only analysis effort. Such 2D ReMi surveys have diversified the application of ReMi

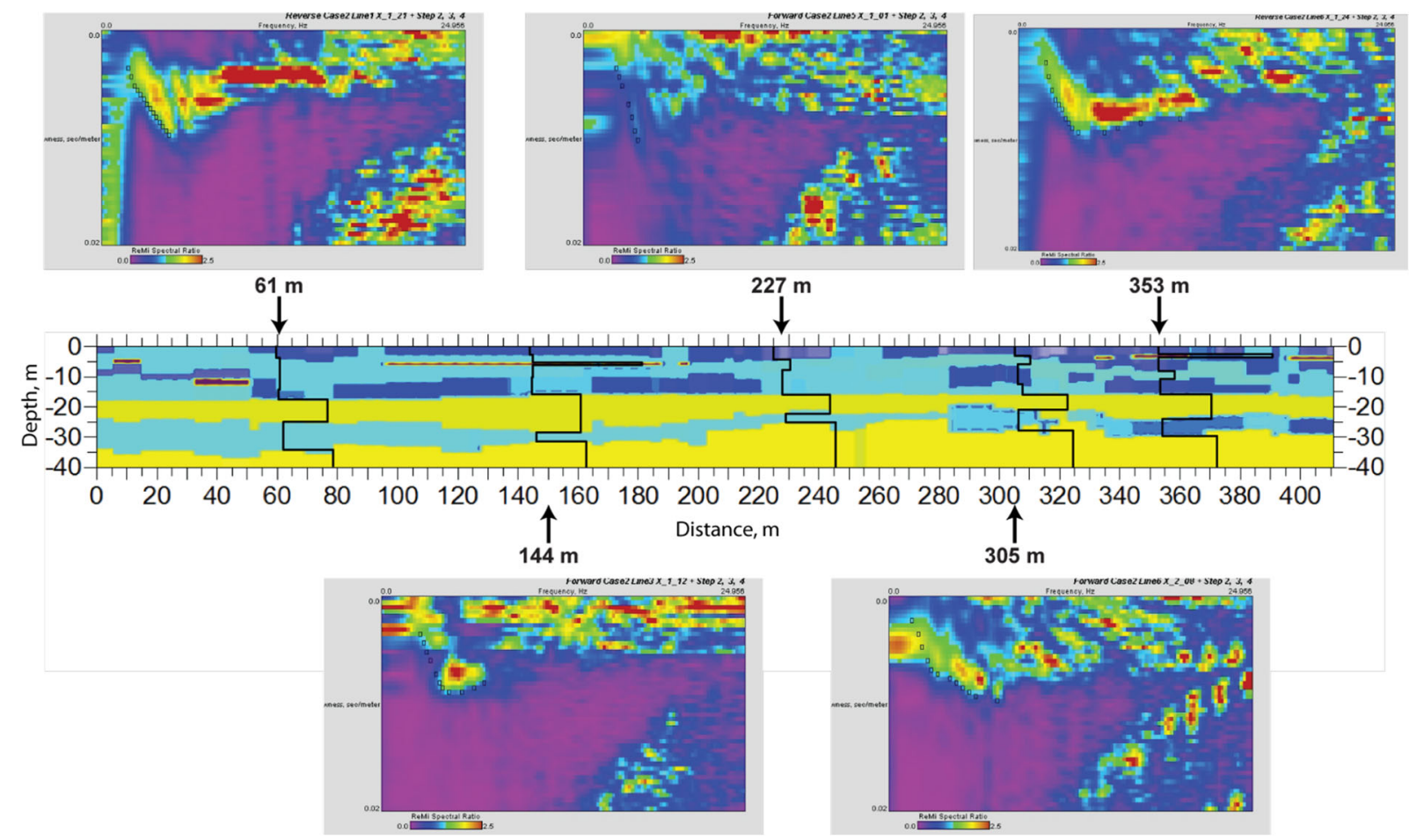

Fig. 6 Example of a two-dimensional ReMi analysis performed for an engineering evaluation at shallow depths. ReMi slownessfrequency $p$ - $f$ spectral images, upper and lower row, are computed on dozens of overlapping sub-arrays at intervals through a 410-mlong multichannel ReMi array. Picking the lowest-velocity envelope on each $p$ - $f$ image and modeling the picks for a velocity vs. depth profile centered on each sub-array allows assembly of a $2 \mathrm{D}$ section, center row, showing lateral as well as vertical distribution of low velocities (cool colors) and high velocities (warm colors) 


Fig. 7 Example of two-dimensional deep ReMi results obtained in 2012 from the Reno-area, Nevada, basin (Pancha et al. 2017c). Arrays of 30 sensors 3 and $6 \mathrm{~km}$ long determined shear-wave velocities to depths of $1000 \mathrm{~m}$, to the Miocene volcanic basement. Cool colors show low velocities and warm colors high velocities. The lower panel compares Line 2 velocities against the results of the geophysical gravity analyses of Plio-Pleistocene sedimentary basin thickness by Washoe County (Cashman et al. 2012) and by Abbott and Louie (2000). Z1.5 is the minimum depth in the section at which shear-wave velocity exceeds $1.5 \mathrm{~km} / \mathrm{s}$

in civil engineering, for foundation design, pretrenching surveys, and karst and landslide hazards assessment (Pullammanappallil 2006).

\subsection{Deep refraction microtremor surveys}

Although initially developed by Louie (2001) for determination of average shear-wave velocities to $30 \mathrm{~m}$ depth (Vs30), the surface-wave theory behind ReMi technique can be applied to a multitude of applications at various scales, with the array configuration and data acquisition adjusted accordingly. The ability of any surface-wave seismic array to image velocity structure at any depth depends on the capability of the array to capture ground motion at wavelengths that sample the target depths. The wavelength content of the recorded data depends on several factors. These include the array length, geophone spacing, geophone frequency (the lowerfrequency limit of motion detection), the time duration of the data records, and the frequency content of the noise sources producing the recorded ground motions. Typically, the depth of penetration of the recorded and modeled wavefield is roughly half the array length. Longer arrays and lower frequency geophones ensure that the longer-wavelength Rayleigh waves that sample deeper into the Earth's structure are captured by the recorded seismic data. Many studies used the ReMi methodology with extended array lengths to successfully image subsurface velocity structure down to $200 \mathrm{~m}$ depth. Total array length should generally be greater than twice the maximum target depth. Rayleigh waves are most sensitive to velocities and structures that are within a half-wavelength of the surface. To properly time the velocity of such a wave, the sensor array needs to be at least as long as the wavelength.

We have extended the range of $2 \mathrm{D}$ refraction microtremor analysis to kilometer depths, completing several deep-basin shear-wave velocity measurement programs for the US Geological Survey. Figure 7 shows the location and results of the 2012 deep ReMi surveys in Reno, Nevada, USA (Pancha et al. 2017c), over the deepest point of the city's sedimentary basin. That initial survey recorded three arrays of thirty, $4.5 \mathrm{~Hz}$ vertical geophone sensors 3 or $6 \mathrm{~km}$ long, for more than $4 \mathrm{~h}$ per array. Default record lengths of $60 \mathrm{~s}$ were initially analyzed. Although dispersive energy was evident in these time records, energy at low frequencies (below $1.0 \mathrm{~Hz}$ ) that defines deeper structure was not prominent. Surface waves with longer wavelengths sample deeper into the geologic structure. Longer time intervals of $120 \mathrm{~s}$ were therefore required to capture their motion. The $p$ - $f$ images (shown in Pancha et al. 2017c) allowed reliable picking of fundamental-mode Rayleigh dispersion to frequencies as low as $0.30 \mathrm{~Hz}$. Two-dimensional modeling recovered shear velocities at depths greater than $1000 \mathrm{~m}$, providing thorough characterization of the basin. Extending a velocity isosurface through the sections at a value of $1.5 \mathrm{~km} / \mathrm{s}$ provides an assessment of the depth of basement (Miocene volcanics here), often called "Z1.5." This ReMi-derived basement depth falls between alternative geophysical gravity and geologic analyses of basement depth (Abbott and Louie 2000; Cashman et al. 2012), in the lower part of Fig. 7.

In 2014, the US Geological Survey funded a second survey, in the northeastern part of the Reno-area basin, under the City of Sparks, Nevada. Changing the survey parameters to arrays of sixty, $4.5-\mathrm{Hz}$ sensors $3 \mathrm{~km}$ long allowed good definition of the 0.6-km-deep basin floor, along with the edges of the basin (Pancha and Pullammanappallil 2014). Gravity constraints in that subbasin were not as good as in the deeper western sub-basin (Abbott and Louie 2000; Cashman et al. 2012), giving additional value to the deep ReMi results. A 2015 survey of two 3-km-long arrays crossed the center of the Renoarea basin, between the 2012 and 2014 survey areas (Pullammanappallil 2016). This survey also used the shorter, denser arrays, reliably measuring dispersion phase velocities to frequencies as low as $0.60 \mathrm{~Hz}$. The shearwave-velocity cross sections suggest that a previously known west-dipping normal fault (Cashman et al. 2012) offsets the floor of the sedimentary basin by more than 100 $\mathrm{m}$ (Pullammanappallil 2016). The Miocene volcanic basin floor throughout the Reno-area basin shows a shear-wave velocity of 2000-2300 m/s.

The 2012 surveys in Reno were accompanied by a 6km-long deep ReMi array in South Lake Tahoe, Calif., funded by Optim and the University of Nevada. This survey imaged shear velocity to the basin floor, as deep 
as $700 \mathrm{~m}$. But the Mesozoic granitic and metamorphic Tahoe basin floor has a shear velocity of $3200 \mathrm{~m} / \mathrm{s}$, substantially above the $2300 \mathrm{~m} / \mathrm{s}$ shear velocity of the Miocene volcanic floor of the Reno-area basin. In March 2016, The Univ. of Nevada recorded two deep ReMi arrays of 90, $4.5 \mathrm{~Hz}$ vertical sensors, 15 and $22 \mathrm{~km}$ long, crossing the Reno-area basin west to east and north to south. Early data analyses suggest that the arrays have detected the $2300 \mathrm{~m} / \mathrm{s}$ to $3200 \mathrm{~m} / \mathrm{s}$ shearvelocity interface at $1-2 \mathrm{~km}$ depth, representing the floor of the Miocene basin's volcanic fill, with Mesozoic bedrock below. This interface is visible in the mountains around the margins of the Reno-area basin (Cashman et al. 2012). These efforts assist delineating the geometry and the shear-wave velocity structure of the Renoarea basin with sufficient detail to be able to improve the modeling of ground shaking and basin effects towards seismic hazard assessment. As well, they suggest the use of deep ReMi for geological basin analysis and resource characterization.

\section{Conclusion}

In closing, following best practices for ReMi modeling will assist practitioners in creating velocity profiles with state-of-the-art reliability. Since the original 2001 paper (Louie 2001), the ReMi technique has been applied on a wide variety of site conditions ranging from hard-rock sites to deep, soft basin fill; on planar topography and on steep hill slopes; and has imaged a range of buried cultural features (e.g., tunnels, culverts, building foundations). The application of ReMi over such varying conditions has improved ReMi interpretation practices and allowed the development of $2 \mathrm{D}$ ReMi and Deep ReMi. But the current state of the art of dispersion modeling needs many improvements, to allow input of a priori information (e.g., interface depths, velocity of geological units), to extend to lateral velocity heterogeneity beyond 1-D shear-velocity versus depth profiles, and to invert for velocities directly from $p$ - $f$ plots without picking dispersion data. The ongoing analysis of ReMi from a variety of applications and subsurface conditions facilitates modeling developments.

Acknowledgements The Consortium of Organizations for Strong Motion Observation Systems (COSMOS) and a group of
North American power utility companies, consisting of Southern California Edison and Pacific Gas and Electric, identified the need for these guidelines for best-practices and provided funding and encouragement to facilitate the project. Open Access publication fees for this paper were directly funded by COSMOS. This material is also based upon work supported by the US Geological Survey under Cooperative Agreement No. G17AC00058. The views and conclusions contained in this document are those of the authors and should not be interpreted as representing the opinions or policies of the US Geological Survey. Mention of trade names or commercial products does not constitute their endorsement by the US Geological Survey. The authors thank Alan Yong of the US Geological Survey, Pasadena Office, for coordinating this issue, and Bill Stephenson of the US Geological Survey, Golden, for reviews and improvements to this manuscript.

Code availability ReMi software is copyright 2020 Optim Earth, Inc. and cannot be distributed.

Funding Support for research and development of the ReMi technology has come from the University of Nevada, Reno, and notably for many decades from Optim Earth, Inc.

Data availability Publicly funded datasets and analyses such as those represented in Figs. 1, 2, and 7 are available to all. Rosrine suspension-logger profiles are available from SCEC.org. ReMiderived shear-wave velocity profile results, summary Vs30 values, $p$ - $f$ images, and fundamental-mode Rayleigh-wave dispersion picks from more than 800 sites in California, Nevada, and New Zealand are available from the ReMi Vs(z) Profile Archive (Louie 2020) at sites.google.com/view/vs-profile-archive. The Archive credits dozens of funding sources, and links to final project reports. The urban ReMi transects published by Scott et al. (2004, 2006) and Thelen et al. (2006), as well as more recent Deep ReMi recordings have array waveform records archived at the Incorporated Research Institutions for Seismology Data Management Center (IRIS-DMC). Search at ds.iris. edu/SeismiQuery/assembled.phtml for assembled waveform data sets with the PI name "Louie." Commercially acquired data and analyses such as those represented in Figs. 3 and 6 remain the property of Optim Earth, Inc. and/or their clients, and cannot be made publicly available. The site-classification results from 10 ,722 Vs30 measurements of the Clark County Parcel Map (Pancha et al. 2017a; Fig. 5) are available from the Clark County GIS system at gisgate.co.clark.nv.us/ow/ (under the "hamburger" options menu select the "Seismic" map type). Parcel Map shearvelocity profiles and array data are proprietary to Optim Earth and cannot be distributed.

\section{Declarations}

Competing interests The ReMi technology is owned by the University of Nevada, Reno, and licensed exclusively to Optim Earth, Inc. (www.optimsoftware.com). Optim pays royalties to the University based on their commercial revenues from ReMi. As inventor of the technology, under University policy, John Louie personally receives a share of those royalties. 
Open Access This article is licensed under a Creative Commons Attribution 4.0 International License, which permits use, sharing, adaptation, distribution and reproduction in any medium or format, as long as you give appropriate credit to the original author(s) and the source, provide a link to the Creative Commons licence, and indicate if changes were made. The images or other third party material in this article are included in the article's Creative Commons licence, unless indicated otherwise in a credit line to the material. If material is not included in the article's Creative Commons licence and your intended use is not permitted by statutory regulation or exceeds the permitted use, you will need to obtain permission directly from the copyright holder. To view a copy of this licence, visit http://creativecommons.org/licenses/by/4.0/.

\section{References}

Abbott RE, Louie JN (2000) Depth to bedrock using gravimetry in the Reno and Carson City, Nevada area basins. Geophysics 65:340-350

Cashman PH, Trexler JH, Widmer MC, Queen SJ (2012) Post2.6 Ma tectonic and topographic evolution of the northeastern Sierra Nevada: The record in the Reno and Verdi basins. Geosphere 8(5):972-990

Claerbout JF (1992) Earth Soundings Analysis: Processing Versus Inversion. Blackwell Scientific Publications, Cambridge, Mass.

Flinchum BA, Louie JN, Smith KD, Savran WH, Pullammanappallil SK, Pancha A (2014) Validating Nevada ShakeZoning predictions of Las Vegas basin response against 1992 Little Skull Mtn. earthquake records. Bull Seismol Soc Am 104(1):439-450 Preprint with color figures at Louie.pub

Garofalo F, Foti S, Hollender F, Bard PY, Cornou C, Cox BR, Ohrnberger M, Sicilia D, Asten M, Di Giulio G, Forbriger T, Guillier B, Hayashi K, Martin A, Matsushima S, Mercerat D, Poggi V, Yamanaka H (2016) InterPACIFIC project: Comparison of invasive and non-invasive methods for seismic site characterization. Part I: Intra-comparison of surface wave methods. Soil Dyn Earthq Eng 82:222-240

Heath K, Louie JN, Biasi G, Pancha A, Pullammanappallil S (2006) Blind tests of refraction microtremor analysis against synthetic models and borehole data. In: Proceedings of the Managing Risk in Earthquake Country Conference Commemorating the 100th Anniversary of the 1906 Earthquake, April 18-22. Calif, San Francisco, 10 pp

Langenheim VE, Grow J, Miller JJ, Davidson JD, Robison E (1998) Thickness of Cenozoic deposits and location and geometry of the Las Vegas Valley shear zone, Nevada, based on gravity, seismic-reflection, and aeromagnetic data. US Geol Survey Open-File Report:OF98-O576. https://doi. org/10.3133/ofr98576 https://pubs.usgs.gov/of/1998/0576 /report.pdf

Langenheim VE, Grow J, Jachens RC, Dixon GL, Miller JJ (2001) Geophysical constraints on the location and geometry of the Las Vegas Valley shear zone, Nevada. Tectonics 20:189-209

Liu Y, Luke B, Pullammanappallil S, Louie J, Bay J (2005) Combining active- and passive-source measurements to profile shear wave velocities for seismic microzonation. In:
Boulanger RW et al (eds) ASCE GSP 133In Earthquake Engineering and Soil Dynamics, $\mathrm{p} 14$

Louie JN (2001) Faster, better: shear-wave velocity to 100 meters depth from refraction microtremor arrays. Bull Seismol Soc Am 91(2):347-364

Louie J (2015): Clark County and Reno/Tahoe: Advancing earthquake hazard assessment with physics and geology. Proceedings of the Basin and Range Seismic Hazard Summit III, 12-16 Jan Salt Lake City 10 pp

Louie JN (2020): ReMi Vs(z) Profile Archive (Version 2.0.0) [Data set]. Zenodo. http://doi.org/10.5281/zenodo.3951865

Louie JN, Pullammanappallil SK, Pancha A, West T, Hellmer W (2011) Earthquake hazard class mapping by parcel in Las Vegas Valley. American Society of Civil Engineers (ASCE) 2011 Structures Congress, Las Vegas, Nevada (April 14):12 pp. https://doi.org/10.1061/41171(401)156

Louie JN, Pullammanappallil SK, Pancha A, Hellmer WK (2012) Earthquake hazard class mapping by parcel in Las Vegas Valley. In: Proceedings of the American Society of Civil Engineers (ASCE) GeoCongress 2012, Oakland, Calif, pp 25-29 10 pp. Preprint at Louie.pub

Naphan D, Louie JN, West LT, Pancha A, Honjas B, Kissane B (2019 in review): Effects of energy directionality on ReMi ${ }^{\mathrm{TM}}$ analysis. Bulletin of the Seismological Society of America, revised 3 November, 24 pp. Preprint at Louie.pub

NEHRP (2020) (National Earthquake Hazards Reduction Program): Recommended Seismic Provisions for New Buildings and Other Structures (FEMA P-2082-1). In 2020 Edition Volume I: Part 1 Provisions and Part 2 Commentary, prepared for the Federal Emergency Management Agency of the U.S. Department of Homeland Security by the Building Seismic Safety Council of the National Institute of Building Sciences

Page WR, Dixon GL, Workman JB (1998) The Blue Diamond landslide: a Tertiary megabreccia deposit in the Las Vegas area, Clark County, Nevada. Geological Society of America Map and Chart Series MCH083:11

Pancha A, Pullammanappallil S (2014): Determination of 3Dvelocity structure across the northeastern portion of the Reno area basin. Final Technical Report to the U.S. Geological Survey, External Grant Award No. G14AP00020, 27 pp. http://earthquake.usgs. gov/research/external/reports/G14AP00020.pdf

Pancha A, Anderson JG, Louie J, Pullammanappallil S (2008) Measurement of shallow shear wave velocities at a rock site using the ReMi technique. Soil Dyn Earthq Eng 28:522-535

Pancha A, Louie J, Pullammanappallil S (2017a): Clark County's Earthquake Parcel Map: Comprehensive community resilience for $\$ 20$ per household. 16th World Conference on Earthquake Engineering, Santiago, Chile, 9-13 January, 12 $\mathrm{pp}$

Pancha A, Pullammanappallil SK, West LT, Louie JN, Hellmer WK (2017b) Large scale earthquake hazard class mapping by parcel in Las Vegas Valley, Nevada. Bull Seismol Soc Am 107:741-749. https://doi.org/10.1785/0120160300

Pancha A, Pullammanappallil S, Louie J, Cashman PH, Trexler JH (2017c) Determination of 3D basin shear-wave velocity structure using ambient noise in an urban environment: A case study from Reno, Nevada. Bulletin of the Seismological Society of America, 107, no 6(December):3004-3022. https://doi.org/10.1785/0120170136 
Pullammanappallil S (2006): Geotechnical and geophysical case studies involving the Refraction Microtremor (ReMi) method for shear wave profiling. 2006 Highway Geophysics Conference, December 5-7, St. Louis, Missouri

Pullammanappallil S (2016): Determination of deep shear-velocity structure across the Reno-area basin. Final Technical Report to the U.S. Geological Survey, External Grant Award No. G15AP00055, 31 pp. http://earthquake.usgs. gov/research/external/reports/G15AP00055.pdf

Scott JB, Clark M, Rennie T, Pancha A, Park H, Louie JN (2004) A shallow shear-wave velocity transect across the Reno, Nevada area basin. Bull Seismol Soc Am 94(6):2222-2228

Scott JB, Rasmussen T, Luke B, Taylor W, Wagoner JL, Smith SB, Louie JN (2006) Shallow shear velocity and seismic microzonation of the urban Las Vegas, Nevada basin. Bull Seismol Soc Am 96(3):1068-1077

Stephenson WJ, Louie JN, Pullammanappallil S, Williams RA, Odum JK (2005) Blind shear-wave velocity comparison of
ReMi and MASW results with boreholes to $200 \mathrm{~m}$ in Santa Clara Valley: Implications for earthquake ground motion assessment. Bull Seismol Soc Am 95(6):2506-2516

Thelen WA, Clark M, Lopez CT, Loughner C, Park H, Scott JB, Smith SB, Greschke B, Louie JN (2006) A transect of 200 shallow shear velocity profiles across the Los Angeles Basin. Bull Seismol Soc Am 96(3):1055-1067

Wills CJ, Petersen M, Bryant WA, Reichle M, Saucedo GJ, Tan S, Taylor G, Treiman J (2000) A site conditions map for California based on geology and shear-wave velocity. Bull Seismol Soc Am 90(6B):S187-S208

Publisher's note Springer Nature remains neutral with regard to jurisdictional claims in published maps and institutional affiliations. 